\title{
Dorsal hippocampal CREB is both necessary and sufficient for spatial memory
}

\author{
Melanie J. Sekeres, ${ }^{1,2}$ Rachael L. Neve, ${ }^{3}$ Paul W. Frankland, ${ }^{1,2,4}$ and \\ Sheena A. Josselyn ${ }^{1,2,4,5}$ \\ ${ }^{1}$ Program in Neurosciences and Mental Health, Hospital for Sick Children, Toronto, Ontario M5G 1 X8, Canada; ${ }^{2}$ Department of \\ Physiology, University of Toronto, Toronto, Ontario M5G 1X8, Canada; ${ }^{3}$ Department of Brain and Cognitive Sciences, \\ Massachusetts Institute of Technology, Cambridge, Massachusetts 02139, USA; ${ }^{4}$ Institute of Medical Sciences, University of Toronto, \\ Toronto, Ontario M5G 1X8, Canada
}

\begin{abstract}
Although the transcription factor CREB has been widely implicated in memory, whether it is sufficient to produce spatial memory under conditions that do not normally support memory formation in mammals is unknown. We found that locally and acutely increasing CREB levels in the dorsal hippocampus using viral vectors is sufficient to induce robust spatial memory in two conditions that do not normally support spatial memory, weakly trained wild-type (WT) mice and strongly trained mutant mice with a brain-wide disruption of CREB function. Together with previous results, these findings indicate that CREB is both necessary and sufficient for spatial memory formation, and highlight its pivotal role in the hippocampal molecular machinery underlying the formation of spatial memory.
\end{abstract}

[Supplemental material is available online at http://www.learnmem.org.]

A fundamental goal of neuroscience is to understand how memories are formed. One approach to study this question involves examining the molecular machinery underlying memory formation to determine the molecules that are necessary and sufficient for memory formation (Dudai 2002). To investigate whether a molecule is necessary for memory formation, experiments typically interfere with the function of this molecule and determine whether memory is disrupted, thereby inferring the normal function of a molecule from dysfunction. Dozens of molecules satisfy this criterion (Grant 2003). To examine sufficiency, experiments may enhance the function of a molecule and determine whether memory can be artificially induced under conditions that do not normally support memory formation, thereby mimicking normal memory formation. Few, if any, molecules satisfy this criterion in mammals.

The CREB ( $\underline{\mathrm{c} A M P} / \underline{\mathrm{Ca}}^{2+}$ response element binding protein) family of transcription factors is implicated in memory in a variety of species (Bourtchuladze et al. 1994; Yin et al. 1994; Guzowski and McGaugh 1997; Bartsch et al. 1998; Han et al. 2007). Spatial memory formation, as assessed in the watermaze, critically relies on the hippocampus, including the dorsal CA1 region of the hippocampus (Morris et al. 1982). Disrupting CREB function in the dorsal hippocampus using a variety of techniques typically impairs watermaze performance (Bourtchuladze et al. 1994; Guzowski and McGaugh 1997; Pittenger et al. 2002; but see Balschun et al. 2003), suggesting that hippocampal CREB is necessary for spatial memory formation. Whether CREB is sufficient for spatial memory formation, however, remains unknown.

Accordingly, we examined whether increasing CREB function specifically in the dorsal hippocampus is sufficient to induce spatial memory under two conditions that do not normally support memory formation. To locally and acutely increase

\footnotetext{
${ }^{5}$ Corresponding author.
}

E-mail sheena.josselyn@sickkids.ca; fax (416) 813-7717.

Article is online at http://www.learnmem.org/cgi/doi/10.1101//m.1785510.
CREB function, we used replication-defective herpes simplex viral (HSV) vectors. We used HSV because, unlike many other viruses, HSV is naturally neurotropic (Fink et al. 1996). To increase CREB levels and function, we microinjected HSV encoding wild-type (WT) CREB (CREB vector). As a control, we microinjected HSV encoding a mutant form of CREB that cannot be phosphorylated at the key Ser133 residue and, therefore, cannot activate transcription (CREB ${ }^{\mathrm{S} 133 \mathrm{~A}}$, mCREB vector) (Gonzalez et al. 1989). To visualize HSV infection, each transgene was fused with green fluorescent protein (GFP). As an additional control, we microinjected HSV encoding LacZ fused with GFP (Control vector). Microinjection of these vectors produced robust transgene expression that was localized to the dorsal CA1 region of the hippocampus (Fig. 1A).

In our first no-memory condition, we increased CREB levels in WT mice before subthreshold training in the watermaze (three trials per day, for $3 \mathrm{~d}$ ) that is not normally sufficient to produce spatial memory. During the probe test conducted after this weak training, WT mice with Control vector showed no evidence of spatial memory; mice with Control vector searched the target zone (that previously contained the platform) and the other equally sized zones similarly (Fig. 1B,C). In contrast, mice with CREB vector showed strong spatial memory; these mice searched selectively in the target zone of the pool in which the platform was previously located (Fig. 1B,C; Supplemental Fig. 1). This enhancement in spatial memory depended on overexpression of intact CREB protein because mice microinjected with MCREB vector (with a single point mutation in the key Ser133 site of CREB) showed no evidence of a spatial memory (Fig. 1B,C).

We next tested whether the enhancement in watermaze performance produced by the CREB vector depended on a representation of the distal cues that surround the watermaze. Accordingly, we trained an additional group of WT mice with CREB vector using the weak protocol in the watermaze and assessed performance in two probe tests in which the distal cues were (1) present or (2) obscured by a black curtain. As before, 
A

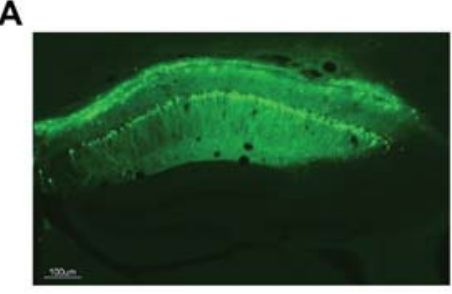

B

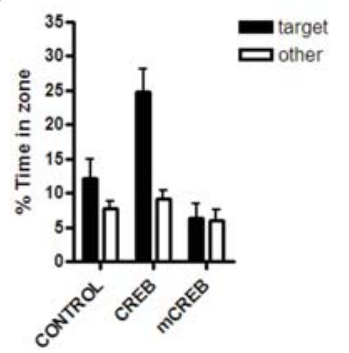

C
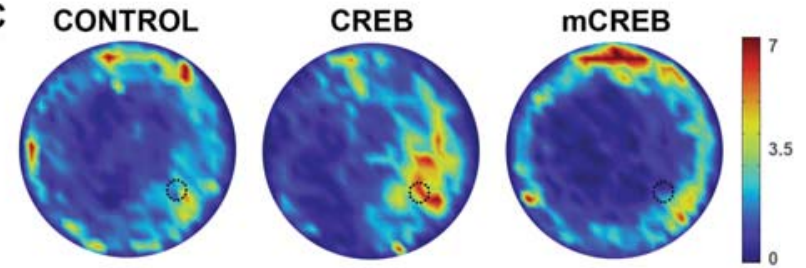

D

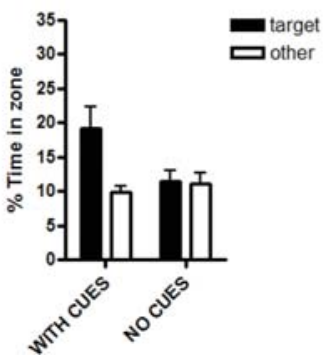

E

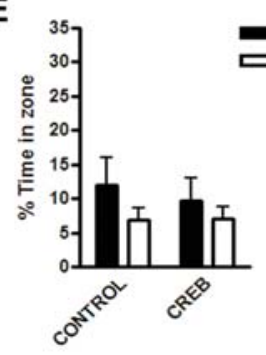

Figure 1. Acutely increasing CREB in the dorsal hippocampus is sufficient to induce spatial memory in undertrained WT mice. $(A)$ Robust, localized transgene expression (GFP, green) following vector microinjection into the CA1 region of the dorsal hippocampus. (B) Mice with Control $(n=13)$ or mCREB $(n=8)$ vector show no spatial memory (mice spent similar amounts of time searching in the target zone of the pool, which previously contained the platform, as in the other equally sized zones) following weak training. However, mice with CREB vector $(n=10)$ showed robust spatial memory after weak training, spending a greater amount of time in the target zone than in the other zones (significant Vector $\times$ Zone $\left[F_{(2,28)}=7.78, P<0.001\right]$, Vector $\left[F_{(2,28)}=9.11, P<\right.$ $0.001]$, Zone $\left[F_{(1,28)}=17.92, P<0.001\right]$ effects). Only mice with CREB vector formed a spatial memory (searched selectively in target zone, post-hoc analysis, $P<0.001$ ). Time spent in target zone was higher in mice with CREB vector than in both mice with Control or mCREB vector, which did not differ $\left(F_{(2,28)}=9.78, P<0.001\right)$. (C) Density plots for grouped data showing the probe test search patterns of mice with CREB, mCREB, or Control vector. Platform position during training was the lower right quadrant. Color scale represents the number of visits per animal per $5 \times 5 \mathrm{~cm}^{2}$ area of the watermaze pool. (D) CREB-enhanced performance in the watermaze is due to spatial memory. Mice with CREB vector $(n=7)$ were trained with the weak protocol, then, given two probe tests in which the extramaze cues were (1) present (with cues) or (2) obscured by a curtain (no cues). Mice spent more time in target, than in other zones of pool when distal cues were present $\left(F_{(1,6)}=9.99, P<0.05\right)$, but spent an equal percentage of time when cues were obscured $\left(F_{(1,6)}=0.03, P>0.05\right)$, indicating that mice with CREB vector relied on distal cues to show enhanced performance in the watermaze. $(E)$ Increasing CREB prior to testing (rather than training) does not affect watermaze performance. Mice microinjected with CREB $(n=7)$ or Control $(n=6)$ vector after (rather than before) weak training did not search selectively in the target zone (no significant Vector $\times$ Zone interaction $\left.\left[F_{(1,11)}=0.0007, P>0.05\right]\right)$.

mice with CREB vector searched selectively in the target zone when the distal cues were present, but no longer showed a preference for the target zone (instead searching the pool randomly) when the distal cues surrounding the pool were obscured (Fig. 1D). The finding that mice with CREB vector did not search selectively in the target zone when the distal cues were obscured indicates that the enhancement in watermaze performance produced by increasing CREB in the dorsal hippocampus critically depended on spatial memory (an accurate, allocentric representation of distal cues surrounding the watermaze). Finally, we examined the effects of increasing CREB in the dorsal hippocampus on probe test performance by microinjecting CREB vector after (rather than before) weak training. Increasing CREB function prior to testing did not enhance watermaze performance as mice randomly searched the pool (Fig. 1E). Besides inducing spatial memory in undertrained mice, CREB vector also further enhanced spatial memory formation in mice trained with a strong watermaze protocol (six trials a day, for 3 d; Supplemental Fig. 2A-D). To examine whether increasing CREB in the dorsal hippocampus alters expression of a previously acquired spatial memory, we microinjected CREB or Control vectors following, rather than before, strong training. In this way, training was conducted with normal (endogenous) CREB levels, and memory expression was assessed with high CREB levels. As expected, before vector microinjection, both groups showed equally robust spatial memory following the strong watermaze training. Increasing CREB levels in the dorsal hippocampus did not affect spatial memory expression: Both mice microinjected with CREB and Control vectors after training showed similarly strong spatial memory (Supplemental Fig. 2E). Therefore, increasing CREB in the dorsal hippocampus is sufficient to produce spatial memory under weak training conditions that do not normally support spatial memory formation.

In our second no-memory condition, we used CREBdeficient $\left(\mathrm{CREB}^{\alpha \delta^{-/-}}\right)$mice that have reduced levels of CREB protein (>90\%) and CREB-DNA binding activity throughout the brain (Pandey et al. 2000; Walters and Blendy 2001). Importantly, these mice show impaired spatial memory formation (Bourtchuladze et al. 1994; Kogan et al. 1997; Hebda-Bauer et al. 2005), although the deficit is sensitive to genetic background and training condition (Kogan et al. 1997; Gass et al. 1998; Graves et al. 2002). In agreement with previous reports (Walters and Blendy 2001; Walters et al. 2003), we found that CREB-deficient mice showed low levels of endogenous CREB protein in the dorsal hippocampus compared with WT littermate mice. However, microinjecting CREB vector into the dorsal hippocampus of CREB-deficient mice increased CREB protein levels in infected neurons only (Fig. 2A).

Further supporting the necessity of CREB for the formation of spatial memory, CREB-deficient mice with Control vector showed no evidence of spatial memory following strong training (six trials a day, for $3 \mathrm{~d}$ ). Specifically, during the probe test CREB-deficient mice did not search selectively in the target zone of the pool and showed high levels of thigmotaxis (the tendency to search in the periphery of the pool) (Fig. 2B-E; Supplemental Fig. 3A,B; Wolfer et al. 1998). Microinjecting the CREB vector completely rescued the spatial memory deficit of CREB-deficient mice (CREB-deficient mice with CREB vector spent a similarly high percentage of time in the target zone of the pool and displayed similarly low levels of thigmotaxis as their WT littermates; Fig. 2B-E; Supplemental Fig. 3A,B). Therefore, acutely increasing CREB levels specifically in the dorsal hippocampus of CREB-deficient mice (with decreased CREB throughout the brain) is sufficient to rescue the spatial memory deficit normally observed in these mice.

The formation of long-term memory is known to require transcription (Davis and Squire 1984). The human genome contains as many as 3000 transcription factors (Babu et al. 2004). Many of these transcription factors have been implicated in mammalian memory formation (e.g., CREB, zif268, C/EBP, AP-1, SRF, BMAL-1, DREAM, MEF2, and Rel/nuclear factor $\kappa \mathrm{B}$ ) (Alberini 
A

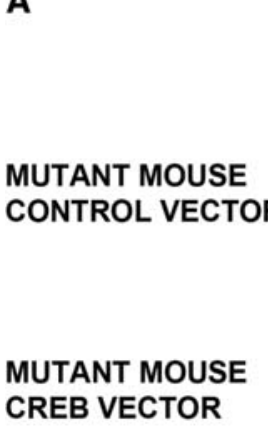

WT MOUSE CONTROL VECTOR
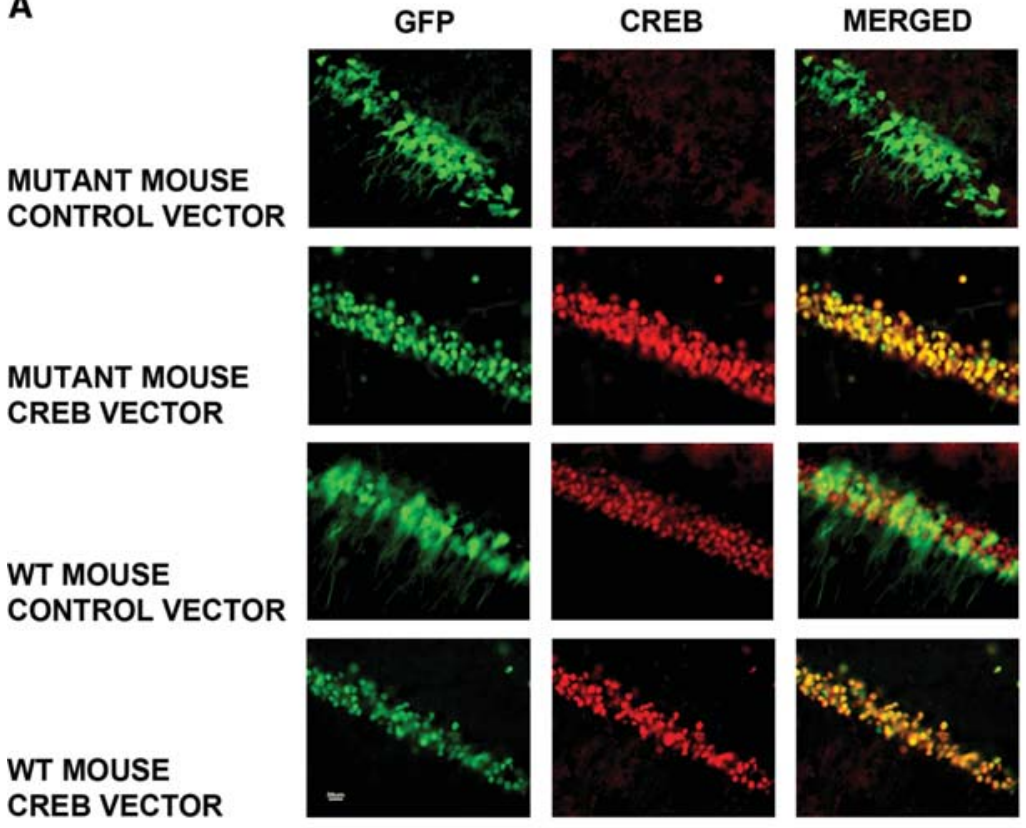

B

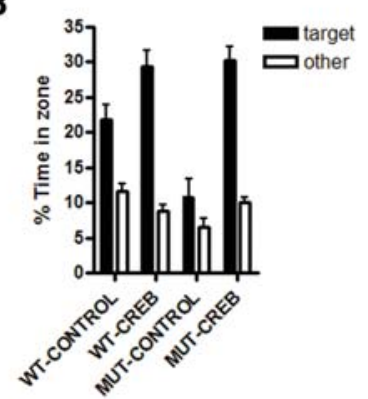

D

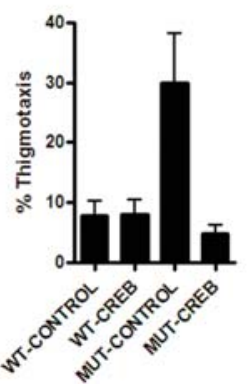

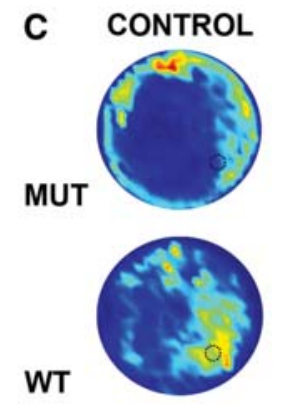

WT

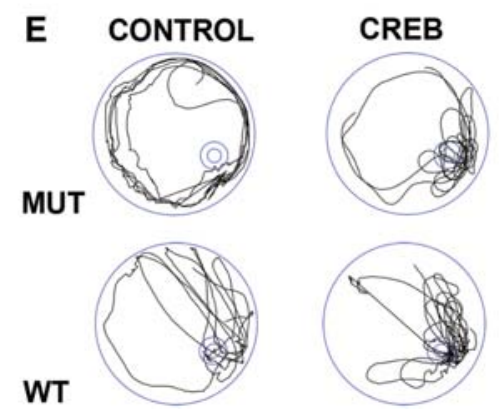

Figure 2. Acutely increasing CREB levels in the dorsal hippocampus is sufficient to rescue the spatial memory deficit of CREB-deficient mice. (A) CREB-deficient mice (Mutant Mouse) microinjected with Control vector (green) show low levels of endogenous CREB protein (red). However, microinjection of CREB vector increases the levels of CREB protein in CREB-deficient mice. (B) CREB-deficient mice (MUT) with Control vector $(n=12)$ show poor spatial memory compared with WT mice with Control $(n=14)$ or CREB $(n=10)$ vectors following strong watermaze training. CREB vector completely reverses the spatial memory deficit in CREB-deficient mice $(n=10$; significant Group $\times$ Zone $\left[F_{(3,42)}=10.14, P<0.001\right]$, Group $\left[F_{(3,42)}=17.68, P<0.001\right]$, Zone $\left.\left[F_{(1,42)}=123.78, P<0.001\right]\right)$. CREB-deficient mice with Control vector did not search selectively in the target zone and spent less time in the target zone than did WT mice with either Control or CREB vector (post-hoc analysis, $P<$ 0.001). In contrast, CREB-deficient mice with CREB vector searched selectively in the target zone $\left(F_{(3,42)}=15.68, P<0.001\right)$ and spent an equal amount of time in the target zone as did WT mice with CREB vector. (C) Watermaze probe density plots for grouped data. (D) The high levels of thigmotaxis (swimming in the periphery of the pool) during the probe test observed in CREB-deficient mice were also rescued by the CREB vector $\left(F_{(3,42)}=6.48, P<0.001\right)$. (E) Representative swim paths for groups during the probe test showing the rescue of spatial memory deficits in the CREB-deficient mice by the CREB vector.

2009). However, no transcription factor (or other molecule, to the best of our knowledge) has been shown to be both necessary for spatial memory formation and sufficient to produce spatial memory under conditions that do not normally support memory formation in mammals. In these studies, we found that locally and acutely increasing CREB in the dorsal hippocampus was sufficient to induce robust spatial memory in two different conditions in which spatial memory is not normally observed. Together with previous findings, these results show that CREB in the dorsal hippocampus is both necessary and sufficient for spatial memory formation, indicating that CREB-mediated transcription is a limiting step in the process of spatial memory formation.

\section{Acknowledgments}

We thank P.J. Ross and M. van den Oever for technical expertise. This work was supported by grants from the Canadian Institutes of Health Research (CIHR; MOP-74650, S.A.J.; MOP-86762, P.W.F.), EJLB Foundation (S.A.J.), and Natural Science and Engineering Research Council (NSERC; S.A.J.). M.J.S. received support from a Restracomp Fellowship (Hospital for Sick Children) and a CIHR Frederick Banting and Charles Best Canada Graduate Scholarships Doctoral Award.

\section{References}

Alberini CM. 2009. Transcription factors in long-term memory and synaptic plasticity. Physiol Rev 89: 121-145.

Babu MM, Luscombe NM, Aravind L, Gerstein M, Teichmann SA. 2004. Structure and evolution of transcriptional regulatory networks. Curr Opin Struct Biol 14: 283-291.

Balschun D, Wolfer DP, Gass P, Mantamadiotis T, Welzl H, Schutz G, Frey JU, Lipp HP. 2003. Does cAMP response element-binding protein have a pivotal role in hippocampal synaptic plasticity and hippocampus-dependent memory? J Neurosci 23: 6304-6314.

Bartsch D, Casadio A, Karl KA, Serodio P, Kandel ER. 1998. CREB1 encodes a nuclear activator, a repressor, and a cytoplasmic modulator that form a regulatory unit critical for long-term facilitation. Cell 95: 211-223.

Bourtchuladze R, Frenguelli B, Blendy J, Cioffi D, Schutz G, Silva AJ. 1994. Deficient long-term memory in mice with a targeted mutation of the cAMP-responsive element-binding protein. Cell 79: 59-68.

Davis HP, Squire LR. 1984. Protein synthesis and memory: A review. Psychol Bull 96: 518-559.

Dudai Y. 2002. Memory from A to Z: Keywords, concepts and beyond. University Press, Oxford, UK.

Fink DJ, DeLuca NA, Goins WF, Glorioso JC. 1996. Gene transfer to neurons using 
herpes simplex virus-based vectors. Annu Rev Neurosci 19: 265-287.

Gass P, Wolfer DP, Balschun D, Rudolph D, Frey U, Lipp HP, Schutz G. 1998 Deficits in memory tasks of mice with CREB mutations depend on gene dosage. Learn Mem 5: 274-288.

Gonzalez GA, Yamamoto KK, Fischer WH, Karr D, Menzel P, Biggs W III, Vale WW, Montminy MR. 1989. A cluster of phosphorylation sites on the cyclic AMP-regulated nuclear factor CREB predicted by its sequence. Nature 337: 749-752.

Grant SG. 2003. Systems biology in neuroscience: Bridging genes to cognition. Curr Opin Neurobiol 13: 577-582.

Graves L, Dalvi A, Lucki I, Blendy JA, Abel T. 2002. Behavioral analysis of CREB $\alpha \delta$ mutation on a B6/129 F1 hybrid background. Hippocampus 12: $18-26$.

Guzowski JF, McGaugh JL. 1997. Antisense oligodeoxynucleotidemediated disruption of hippocampal cAMP response element binding protein levels impairs consolidation of memory for water maze training. Proc Natl Acad Sci 94: 2693-2698.

Han JH, Kushner SA, Yiu AP, Cole CJ, Matynia A, Brown RA, Neve RL, Guzowski JF, Silva AJ, Josselyn SA. 2007. Neuronal competition and selection during memory formation. Science 316: 457-460.

Hebda-Bauer EK, Watson SJ, Akil H. 2005. Cognitive performance is highly sensitive to prior experience in mice with a learning and memory deficit: Failure leads to more failure. Learn Mem 12: 461-471.

Kogan JH, Frankland PW, Blendy JA, Coblentz J, Marowitz Z, Schutz G, Silva AJ. 1997. Spaced training induces normal long-term memory in CREB mutant mice. Curr Biol 7: 1-11.
Morris RG, Garrud P, Rawlins JN, O'Keefe J. 1982. Place navigation impaired in rats with hippocampal lesions. Nature 297: $681-683$.

Pandey SC, Mittal N, Silva AJ. 2000. Blockade of cyclic AMP-responsive element DNA binding in the brain of CREB $\delta / \alpha$ mutant mice. Neuroreport 11: 2577-2580.

Pittenger C, Huang YY, Paletzki RF, Bourtchouladze R, Scanlin $\mathrm{H}_{\text {, }}$ Vronskaya S, Kandel ER. 2002. Reversible inhibition of CREB/ATF transcription factors in region CA1 of the dorsal hippocampus disrupts hippocampus-dependent spatial memory. Neuron 34: 447-462.

Walters CL, Blendy JA. 2001. Different requirements for cAMP response element binding protein in positive and negative reinforcing properties of drugs of abuse. J Neurosci 21: 9438-9444.

Walters CL, Kuo YC, Blendy JA. 2003. Differential distribution of CREB in the mesolimbic dopamine reward pathway. J Neurochem 87: 1237-1244.

Wolfer DP, Stagljar-Bozicevic M, Errington ML, Lipp HP. 1998. Spatial memory and learning in transgenic mice: Fact or artifact? News Physiol Sci 13: $118-123$.

Yin JC, Wallach JS, Del Vecchio M, Wilder EL, Zhou H, Quinn WG, Tully T. 1994. Induction of a dominant negative CREB transgene specifically blocks long-term memory in Drosophila. Cell 79: 49-58.

Received February 23, 2010; accepted in revised form April 20, 2010. 


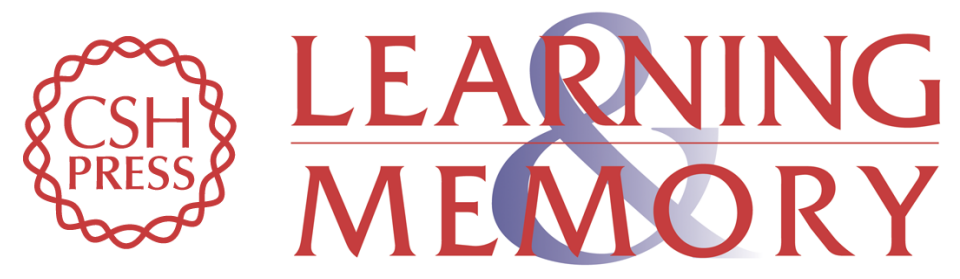

\section{Dorsal hippocampal CREB is both necessary and sufficient for spatial memory}

Melanie J. Sekeres, Rachael L. Neve, Paul W. Frankland, et al.

Learn. Mem. 2010, 17:

Access the most recent version at doi:10.1101//m.1785510

\section{Supplemental http://learnmem.cshlp.org/content/suppl/2010/05/21/17.6.280.DC1 Material}

References This article cites 22 articles, 6 of which can be accessed free at: http://learnmem.cshlp.org/content/17/6/280.full.html\#ref-list-1

\section{License}

Email Alerting

Receive free email alerts when new articles cite this article - sign up in the box at the Service top right corner of the article or click here. 